\title{
Risk assessment and management in the implementation of projects in the rocket and space complex on the basis of commercial effectiveness principles
}

\author{
Alexander Sobol ${ }^{1}$, and Oleg Fadeev ${ }^{1, *}$ \\ ${ }^{1}$ Gazprombank, 117420, Nametkina str., 16, Building 1, Moscow, Russia
}

\begin{abstract}
The paper discusses the possibility of implementing projects in the rocket and space complex on the principles of commercial efficiency without support coming from the government. In the paper, project risks in the implementation of projects in the rocket and space complex are classified. A comprehensive assessment of activities on project risks that can be applied in the rocket and space complex are also described. The paper also develops stages of managing project risks in commercial projects of the rocket and space complex, as well as a scheme of monitoring risks for commercial projects. The paper concludes that it is possible to implement projects in the rocket and space complex without government support using an effective system of risk assessment and management.
\end{abstract}

The implementation of any project in the rocket and space complex (RSC) against the backdrop of instability in the world and Russian economies is fraught with a risk of nonreceipt of the financial, production, and social result that is expected by project participants. The process of implementing a project and making managerial decisions to level potential risks is in the perimeter of continuously emerging risk events almost all the time, which requires timely technical, financial, and organizational stimulation and mitigation. Important in minimizing project risks in the RSC is the issue of considering the possibility of using budget and commercial financing for project implementation. For the actualization and risk management in the implementation of projects in the RSC, one should pay attention to one of the main issues, the answer to which will help determine the vector of further development of space projects.

Is it possible to implement projects in the RSC on the principles of commercial efficiency or only with the participation of state support?

The main purpose of attracting commercial capital and companies for the implementation of projects in the RSC is guaranteed delivery of goods, the possibility of using independent access to outer space, effective expenditure and financial control over the use of funds, a consistent reduction in project costs, and an increase in payload. All this can be achieved due to the optimal set of financial, technical, organizational, and human

* Corresponding author: Oleg.Fadeev@gazprombank.ru 
resources associated with an effectively built risk assessment and management system. American engineer, scientist, and entrepreneur Ilon Mask went down in history when his company Space Exploration Technologies (SpaceX) became the first private company that docked the spacecraft to the international space station, successfully landed the Falcon 9 rocket on the offshore platform, and very significantly reduced project costs. Currently, SpaceX is working on the development of a full-fledged rocket launcher and the simultaneous landing on a platform of three launch vehicles at the same time. SpaceX has plans to deploy more than 4,000 satellites in near-Earth orbit and create a world-wide highspeed network based on them, to increase the launch of rockets every two weeks, and to conduct regular flights to Mars with the help of the world's most powerful rocket carrier Falcon Heavy. The Russian example of implementing commercial projects in RSC is the company Gazprom Space Systems OJSC (GASCOM), which is engaged in the creation, launch, and operation of satellites to provide telecommunications, geoinformation, and aerospace services to the public and corporate sectors. All these achievements are possible and once again confirm that when implementing projects in epy RSC, it is important to use a quality integrated project risk management system.

Currently, the main trend in the space services market is to reduce project costs, increase the spacecraft payload, and rational management of project risks. These components will form the basis for effective competition in the space services market. World state corporations and private commercial organizations are working to create a space product or service being optimal in price and quality. The cost of the launch vehicle is of great importance in solving this problem. RSC-companies are continuously working to reduce costs to improve their competitive advantages in the market. If earlier the cost of launching the Russian Proton and the European Ariane 5 missiles cost $\$ 100$ million and \$200 million, respectively, now the Russian state corporation "ROSKOSMOS" is working to create a light version of the launch vehicle for commercial use (Proton Light), the launch cost of which is estimated already in 50-55 million dollars. And the largest developer of carrier rockets Airbus Safran Launchers in Europe is working on the creation of a universal reusable Ariane 6 missile, the cost of which will be halved compared to the Ariane 5 being used today. The cost of the US rocket Falcon 9 of the company SpaceX is from 56 to 77 million dollars [5].

Increased activities of the RSC commercial companies in the US, Europe, Russia, China, and India clearly demonstrate the need for civilian space services and give a clear signal about the need for space development in general. The creation and operation of unmanned aerial vehicles (AEWs) also speaks in favor of this. Earlier, the AEWs were used mainly in the state and defense complexes, and now their civil application in the corporate and mass segments is developing more and more actively. The production and operation of modern surveillance, navigation, energy efficiency, and patrols at a lower cost, in a system complex with intelligent processing of the product, create an affordable, safe and environmentally friendly product for the final consumer. The creation of multi-purpose AEWs for civilian use will allow to meet the combined corporate needs for detecting smallsized air, surface, and ground targets, as well as controlling air traffic in remote areas, controlling maritime navigation, developing regional and interregional telecommunications networks, aerial photography, and monitoring the Earth's surface, environmental conditions, works and geological exploration, oil and gas sector, oceanology, etc. Leaders in the implementation of commercial projects for the development, production, and operation of civilian AEWs are DJI (China), Parrot (France), Xiaomi (China), Hover Camera (USA), and AeroVironment (USA) [6]. It is worth noting that Russian AEWs are mainly developed and produced by state corporations of military designation.

When implementing commercial projects in the RSC, as noted earlier, the development of a system for evaluating and managing project risks is of great importance. But before 
systematizing, evaluating, managing, and controlling project risks, it is necessary to identify and classify them, that is, to distribute them to specific groups in accordance with a certain feature. Figure 1 shows the classification of risks, which takes into account the specifics of the commercial project in the RSC.

Classification of risks when implementing commercial projects in RSC

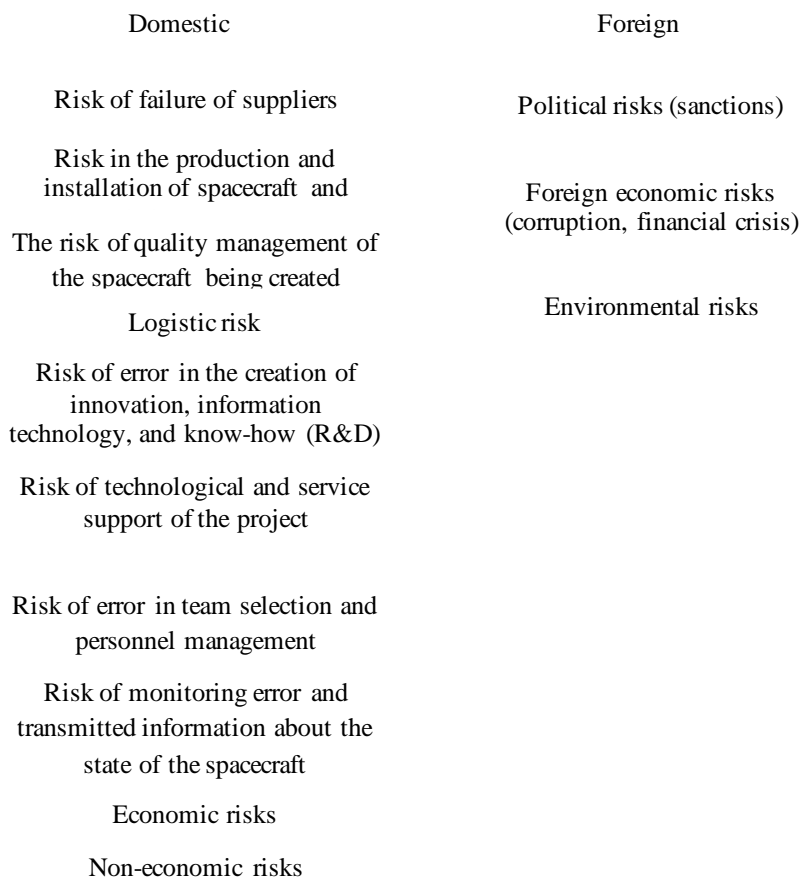

Fig. 1. Classification of risks when implementing projects in the RSC on the principles of commercial efficiency.

Let's say in more detail about the specific project risks that the RSC of Russia has encountered and may face in the future.

As a result of imposing sanctions and banning Russian companies from purchasing high-tech components in the US and Europe, many projects in the RSC of Russia faced certain difficulties. The problem of replacing foreign technologies and components significantly affects the price and quality of the analogues purchased, for example, in the electronic component base. As a consequence, this has a direct impact on final project costs. Nevertheless, the implementation of projects continues under new conditions. An example of a successful commercial project under sanctions in the field of creating and launching a satellite is the implementation of the project by GASCOM, which promptly replaced the necessary replacement parts with analogues and avoided the onset of a critical phase. Like any other projects, commercial projects in the RSC can be increased in value, including due to inadequate financial control and non-compliance with financial discipline. A vivid example are violations of financial control that were identified during the 
implementation of the state-scale project, namely the construction of the Vostochny launch site, and influenced the costs of the project. After carrying out the classification of design risks, managers can reliably establish the individual significance of each risk, conduct its analysis, assessment and management, and continue monitoring activities further, thereby creating elements of an effective risk management system.

Assessment of project risk in the RSC is a set of measures that allow to predict the possibility of obtaining additional profit or a certain amount of damage from the risk that has occurred and erroneous untimely management decisions. The size of possible losses from the incoming risk in the project can be acceptable (when there is a threat of a complete loss of profit), critical (when the loss coverage occurs at the expense of project participants, and the loss of profits and revenues is possible), and catastrophic (the loss of all capital and project assets is possible, which could lead to its elimination in the end). The rational organization of any project and an integrated approach to the assessment and management of project risks can be achieved only through the comprehensive use of methods for assessing project risks, their management and monitoring, taking into account the impact of internal (objective and subjective) factors and the external environment (direct and indirect impact).

An integrated approach to the organization of project risk management in the RSC can be achieved by using (a) the methods for assessing project risks being known and described by many experts and (b) the methods being developed (adapted) in the implementation and management of the project, taking into account the impact of individual factors of both internal and external environments. Features of risk management projects in the RSC are the continuity, dynamism, complexity, novelty, and laboriousness. Moreover, the task is to analyze, research, and manage risks, as well as in developing a valuation of measures to prevent and reduce them. An important component of a commercial project in RSC that affects its outcome and effectiveness is the use of methods for evaluating and managing project risks, which would allow managers to promptly and comprehensively take management decisions aimed at preventing risk situations in the process of project implementation and to develop measures to protect against possible technical, personnel, financial, and other losses.

Comprehensive activities to assess the design risks that can be applied in the RSC include searching for and analyzing risks, assessing specific types of risks on the basis of different approaches and methods, identifying internal and external factors that increase or decrease the specific type of risk, determining the financial viability of the project, determining commercial efficiency (effectiveness of investment of financial resources), setting the acceptable level of risk, developing measures, and making management decisions to reduce the level of risk,.

The main methods for assessing project risks that can be applied also in the RSC include expert methods, statistical methods, as well as quantitative and qualitative assessment methods.

Expert methods for assessing project risks include those methods that are built on the knowledge and experience of individual experts and specialists. These methods are suitable in those situations where the required information on the outcomes or the likelihood of their occurrence is not sufficient, or it is not formalized.

The general procedure for assessing project risks in the RSC using expert methods can consist of several stages: analyzing the assignment given to experts in project risk assessment; organizational and methodological preparation of the expert evaluation; selecting experts on the basis of general erudition, logical and analytical thinking, knowledge and skills in a certain professional field; carrying out expert predictive studies or conducting predictive assessments (the main forms of expert evaluation are the rank 
method, the method of scale scores, the method of pairwise comparisons); processing, analyzing predictive research results [3].

Statistical methods for assessing project risks include methods that use statistical criteria for measuring the risk value calculated on the basis of reliable and complete statistical information, for example, such as the average expected value and variability of the possible result.

Conducting a qualitative analysis of project risks begins with the identification of specific types of risks, their analysis and investigation of possible causes of their occurrence. Further, a cost assessment of the possible consequences of damage from the implementation of identified risks and respective measures are being developed to reduce them. This is the specific feature of the qualitative approach in the study of risks, including in commercial RSC projects.

Quantitative analysis of project risks includes the conducted qualitative analysis and the initial data of the project business plan. The task of quantitative analysis is the numerical measurement of the changing factors of the project, being tested for risk and the behavior of its effectiveness criteria [3].

Most other known methods are described in the literature widely and accurately. All of them have their advantages and disadvantages. For example, the European Space Agency's Risk Management Program (ESA) is based primarily on qualitative methods for assessing project risks. Conversely, the NASA Program uses predominantly quantitative methods based on statistics $[1 ; 2]$, where the analysis of more than 350 projects is the initial data. A distinctive feature of the methods in assessing the risks of the NASA program from one the ECA uses is the division of types of risks into quantitative and qualitative ones using the procedure "TRIAG," which implies the allocation of high, medium, and low reliability estimates from initially qualitatively assessed risks.

It should be noted that there are no universal methods for assessing project risks. The most effective and correct approach is the use of an integrated and system approach relying on various methods for assessing project risks in commercial projects in the RSC, as well as timely introducing additional methods or eliminating those that have lost relevance. Therefore, the important processes in the implementation of any project are the identification, evaluation, and management of project risks.

To improve the quality of risk management in commercial projects in the RSC, it is necessary to correctly assess and effectively manage independent and unrelated risks, detailing the many factors of potential risk that are interrelated and correlated with each other. The design of the spacecraft, the development of a prototype, the ground-breaking experimental testing of the details of operating systems and apparatus as a whole, the production of a standard product, the installation of launch systems, the launching of a prototype, - all these stages of any space project involve long training periods, organizational activities and may be at risk of implementing risky events. To reduce the likelihood of these events, an additional article of financing for insurance is necessarily provided. Insurance is an important and expensive method of reducing risk when implementing projects in the RSC on the principles of commercial efficiency. At present, project insurance costs are about $30 \%$ of the cost of launching, whereas this cost was 15$18 \%$ about 10 years ago. The increase in value is associated with negative statistics of launches of carrier rockets and attraction of foreign insurance companies to cover insurance project risk due to the limited financial capacity of the domestic insurance market. These aspects are very important to consider when planning the project budget. For example, in its commercial activities, GASCOM applies insurance, which allowed it to timely and painlessly eliminate the risk of the project to create and launch a satellite. Once the design risks are identified and evaluation methods are determined, it is necessary to proceed to their management. 
Risk management of commercial projects in the RSC is to reduce the likelihood of their occurrence, the development of measures to eliminate them, to compensate or reduce and minimize the possible damage. Leveling and prevention from the implementation of possible damage in the risk management system is achieved through the use of identification and retrieval, analysis and evaluation, the development and implementation of risk management, the adaptation of a new model, the subsequent monitoring of the measures being implemented to manage them. Risk management is a comprehensive, systematic, and iterative process of optimizing project resources. Next, the authors developed a sequence of consideration and creation of stages for the formation of a project risk management system in the implementation of commercial projects in the RSC.

The first stage, preparatory, involves preliminary work and preparation for the formation of a project risk management system. To achieve this stage, the work should be carried out in three main directions. First, it is necessary to determine the priorities for managing project risks and policies for the formation and structuring of an integrated project management system in the RSC. Second, one should form a specialized unit, a team responsible in the process of project implementation, for coordinating the activities of individual experts and specialists, consolidating, analyzing information, developing methodology and documentation for work on creating and adapting a project risk management mechanism. Thirdly, it is necessary to draw up and approve a plan for managing project risks. The work plan is developed by the core unit and approved by the project managers.

At the second stage, a diagnostic, comprehensive financial and management analysis of the project participants is conducted, as well as an assessment of the situation in the market of space services, marketing, and risky audit are taking place. As a result of a comprehensive analysis, external and internal threats are identified, risk-determining factors are identified, the project cost is calculated.

Depending on the situation of participants and certain existing threats to the project implementation, the target orientation of the system being developed is formed; the processes of strategic, tactical, and operational management of project risks are specified. Further, the overall risk management program is developed, which consists of individual elements and business processes of each participant. Based on this program and the first phase of the plan, a business plan for managing project risks is formed.

The third stage, organizational and administrative, includes the development and adaptation of organizational and administrative documentation of the project, which is an important element of an integrated project risk management system (Figure 2).

The structure of the organizational and administrative documentation must comply with the requirements established by the current legislative and regulatory acts, the interests the RSC enterprises have, credit institutions, and other participants, who are interested in obtaining prompt, reliable, and objective information in project implementation and risk management.

The completion of the organizational and administrative stage and the beginning of the organizational and adaptation stage are the familiarization of the project staff with the adopted documentation and, above all, with the amended Regulation on the Project Risk Management System. To determine the effectiveness of the system, the core unit monitors and reports on the results. Next, project managers make management decisions that are related to the elimination of emerging deviations and inconsistencies in the process of adapting the project risk management system.

Stages of creating a risk management system for the implementation of projects in the RSC are developed by authors on the principles of commercial efficiency, are universal, and can be used by other market participants. The proposed concept allows them to optimize the management of project risks. Project risk management is not limited to the 
stages of creating and forming a risk management system. An important and integral part of risk management in the implementation of commercial projects in the RSC is the subsequent monitoring and control of risks.

Name of the stage

Preparatory

Organizational and administrative

Organizational and adaptive

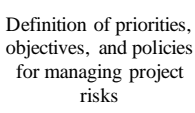
risks

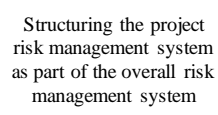

Stage characteristics

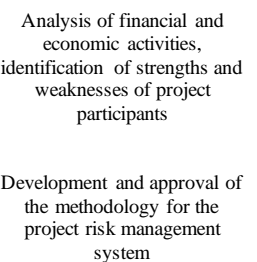

Preparing for adaptation and implementing a project risk management system

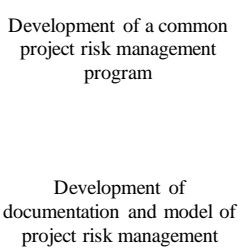

Development of a common project risk management program documentation and model of project risk management
Drawing up a work plan
for the creation of a project risk

management system

Fig. 2. Stages of creating a risk management system for the implementation of projects in the RSC on the principles of commercial efficiency.

Monitoring of project risks, as well as other elements of risk management, is a continuous process that is carried out throughout the life cycle of the project and includes monitoring of identified risks and those that are included in the permanent monitoring register, as well as identification of remaining and potential risks, verification and implementation of risk response operations, and evaluation of the effectiveness of planned activities [4]. The main monitoring objectives include the selection of alternative strategies for managing project risks in the event of those factors that could have a negative impact on project implementation, the adoption of operational corrective actions, and the updating of the risk monitoring, including the project management plan is to be updated. The responsible risk manager must report to the project manager within the deadlines set by the business plan on the effectiveness of the implementation of the risk monitoring plan and of all adjustments and activities that are necessary for proper project management. Monitoring of project risks includes the renewal of the organizational, technological, and financial process, which accumulates knowledge and templates of risk management with a view to their application in the implementation of subsequent projects. The overall risk monitoring scheme for the implementation of projects in the RSC is presented in Figure 3.

The monitoring beginning (input) means the identification, description, and assessment of project risks, as well as a comparison of the results obtained to the approved risk management plan on the basis of the performance report. The newly identified risks are subject to mitigation through control actions and well-known response methods that can also be applied to projects in the RSC. At the output, one gets an updated register of project risks, corrective effects recommended on risks, an updated risk management plan, and a performance report. The beginning of monitoring, evaluation, and management methods, outputs may vary depending on the specifics and scope of the project being implemented. Monitoring becomes implemented if it corresponds to certain management qualitative and quantitative performance criteria. In addition, all the goals of the project should be 
achieved. Systemic, quality, and regular monitoring contributes to improving the commercial efficiency of any project, as well as to improving and promoting the risk management system.

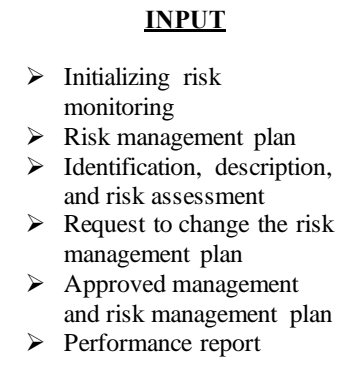

\section{INPUT}

Initializing risk monitoring

Risk management plan

Identification, description, and risk assessment

Request to change the risk

Approved management

Performance report

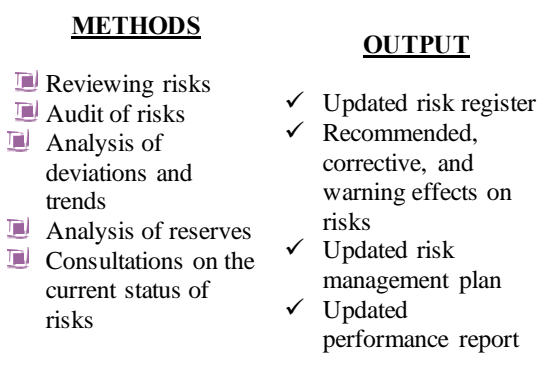

Fig. 3. The scheme for monitoring risks in the implementation of projects in the RSC on the principles of commercial efficiency.

It should be noted that risk assessment and risk management in the implementation of projects in the RSC on the principles of commercial efficiency are not limited by the procedures described above. In particular, the risk manager must pay attention to the correctness and mobility of the chosen strategy and risk management model, taking into account the specifics of the RSC, paying attention to the reliability and relevance of the data used in order to make managerial decisions in the implementation of the project.

In the opinion of the authors, the development of the RSC is one of the leading and priority directions in the development of technologies and innovations on state and corporate scales. The implementation of projects on the principles of commercial efficiency with participation of private capital will determine the level of the scientific and production potential of the country as a whole, contributing to the formation and development of a positive image of the space services market.

Projects in the RSC have a certain specificity, which includes a set of potential risks: science-intensive, high-tech, scale of financing, complex logistics, as well as legal and economic components. A qualitatively constructed risk management system is one of the key factors for deciding whether to implement the project in RSC.

The research conducted by the authors suggests that the implementation and financing of commercial projects in the RSC is possible in case of effective application of a rationally built complex and elastic system of risk assessment and management. The financing of projects in the RSC is always limited on a commercial basis without the participation of government support, because there are (a) critical tasks facing the state, and (b) non-critical ones located in the commercial sphere. Evasion from solving state problems in the RSC is impossible, so there is no question of reducing financing or curtailing programs in such projects, which cannot be said about commercial projects, the implementation of which is possible through continuous improvement of risk management.

\section{References}

1. ESA, ECSS-M-ST-80C-Space project management-Risk management (ESA Requirements and Standards Division, Noordwijk, 2008) 
2. National Aeronautics and Space Administration, NASA risk management handbook (National Aeronautics and Space Administration, Washington, 2013)

3. A. G. Badalova, A. I. Sobol, Theoretical and methodological foundations and methodological tools for assessment and risk management of financial and nonfinancial organizations (Dobroye Slovo, Moscow, 2015)

4. Project Management Institute, A guide to the project management body of knowledge (Project Management Institute, Newtown Square, 2013)

5. Itar-Tass, American booster Falcon 9: dossier (http://tass.ru/info/3262897)

6. Rating of AEW producers (http://bespilotnik.org/company/news/2016/reyting_bpla/) 